\title{
Téoros
}

Revue de recherche en tourisme

\section{Pratiques contemporaines de gestion dans le domaine du tourisme}

\section{Valérie Théberge}

Volume 17, numéro 3, automne 1998

Pratiques contemporaines de gestion dans le domaine du tourisme

URI : https://id.erudit.org/iderudit/1072180ar

DOI : https://doi.org/10.7202/1072180ar

Aller au sommaire du numéro

Éditeur(s)

Université du Québec à Montréal

ISSN

0712-8657 (imprimé)

1923-2705 (numérique)

Découvrir la revue

Citer ce document

Théberge, V. (1998). Pratiques contemporaines de gestion dans le domaine du tourisme. Téoros, 17(3), 54-54. https://doi.org/10.7202/1072180ar d'utilisation que vous pouvez consulter en ligne.

https://apropos.erudit.org/fr/usagers/politique-dutilisation/ 


\section{Pratiques contemporaines de gestion dans Le domaine du tourisme}

Valérie Théberge, bibliothécaire

Centre de documentation touristique UQAM-ACTA

\section{BIBLIOGRAPHIE}

Barnatt, Christopher (1997),

Challenging Reality :

in Search of the Future Organization,

Chichester, J. Wiley.

Belet, Daniel (1998),

Éducation managériale :

pour apprendre et pratiquer

un nouveau métier de manager.

Paris: Montréal, L'Harmattan.

Bergeron, Pierre G. (1997),

La gestion moderne:

une vision globale et intégrée,

Boucherville, Gaètan Morin.

Brilman, Jean (1998),

Les meilleures pratiques de management : au coeur de la performance.

Paris, Éditions d'Organisation.

Consulting and Audit Canada (1997), Ce que les gestionnaires du tourisme ont besoin de savoir : guide pratique pour l'élaboration et l'emploi d'indicateurs du tourisme durable, Madrid, Organisation Mondiale du Tourisme.

Fabre, Michel (1998),

Être authentique, donner du sens: le nouvel élan du management, Paris,

Presses du management.
Ghoshal, Sumantra (1998), Entreprise individualisée : une nouvelle logique de management. Paris, Maxima.

Groupe Innovation (1997), Gérer le savoir, le défi du XXP" siècle, Québec. Groupe Innovation.

Groupe Innovation (1996). L'organisation de demain : gérer la révolution du savoir, Montréal, Publi-Relais.

Harrington, H. James (1997), Le nouveau management selon Harrington : gérer l'amélioration totale, Montréal, Transcontinental.

Hope, Jeremy (1997),

Competing in the Third Wave : the Ten Key Management Issues of the Information Age, Boston, Harvard Business School Press.

Hunot-Clairefond, Florence (1996), Former les nouveaux managers : une pédagogie originale pour développer leurs compétences, Paris, Liaisons.
Julien, Pierre-André (1994),

Pour des PME de classe mondiale : recours a de nouvelles technologies, Montréal. Transcontinental.

Mohrman, Susan Albers (1998), Tomorrow's Organization : Crafting Winning Capabilities in a Dynamic World.

Sansi Francisco, Jossey-Bass.

Robert, Michel, Michel Moisan et Jacques Gauvin, (1996),

La création de produits stratégiques: une approche pure et simple qui vous distinguera de la concurrence, Montréal, Transcontinental.

Salvet, Jean-Marc et

Mary Crozier (1994),

Du management panique ả I'entreprise du XXIe siècle.

Paris, Maxima.

Simonet, Jean (1998), Les stratèges de l'éphèmère: guide du nouveau management. Paris, Éditions d'Organisation. 